Modeling, Identification and Control, Vol. 39, No. 2, 2018, pp. 91-105, ISSN 1890-1328

\title{
Challenges with Respect to Control of Digital Displacement Hydraulic Units
}

\author{
N. H. Pedersen, P. Johansen, T. O. Andersen
}

Fluid Power and Mechatronic Systems, Department of Energy Technology, Aalborg University, Pontoppidanstraede 111, 9220 Aalborg, Denmark. E-mail: nhp@aau.dk, pjo@aau.dk, toa@aau.dk

\begin{abstract}
This paper investigates the many complications arising when controlling a digital displacement hydraulic machine with non-smooth dynamical behavior. The digital hydraulic machine has a modular construction with numerous independently controlled pressure chambers. For proper control of dynamical systems, a model representation of the systems fundamental dynamics is required for transient analysis and controller design. Since the input is binary (active or inactive) and it may only be updated discretely, the machine comprises both continuous and discrete dynamics and therefore belongs to the class of hybrid dynamical systems. The study shows that the dynamical system behavior and control complexity are greatly dependent on the configuration of the machine, the operation strategy, and in which application it is used. Although the system has non-smooth dynamics, the findings show that simple continuous and discrete approximations may be applicable for control development in certain situations, whereas more advanced hybrid control theory is necessary to cover a broader range of situations.
\end{abstract}

Keywords: Digital Displacement Units, Fluid Power, Control, Non-smooth System, Hybrid Systems

\section{Introduction}

Throughout the past decade, there has been an increasing interest in research and development of energy efficient fluid power systems for both conventional cylinder drives Schmidt et al. (2015); Jarf et al. (2016) and power take-off systems Hansen and Pedersen (2016); Hansen et al. (2014); Payne et al. (2007, 2005); Pedersen et al. (2016a); Rampen (2006); Salter et al. (2002). A promising technology is the so called digital displacement machine (DDM), which besides providing great energy efficiency also yields superb scalability. For successful deployment of the technology, proper control of the machine is considered a key challenge to be solved. However, this is a complicated task due to the nonsmooth dynamical behavior.

For most computer controlled systems, either continuous or discrete approximation models are fairly accurate in describing the system macro dynamics. Either linear or non-linear control theory is then applied on these models to ensure stability and obtain the desired performance. However, control of DDM's is different in various ways, since the triggering of a control update is angle dependent and not time dependent. Additionally, the dynamics are highly influenced by the configuration of the machine and how it is operated, as well as in which application it is used. Since control of the digital displacement technology is a relatively unexplored field, an important first step is to identify the control challenges related to the non-smooth machine behavior. This paper provides an overview with respect to development of model based dynamical analysis and feedback control design methods for these machines. The investigation is based on a single module of a DDM with 5 cylinders as illustrated in Fig. 1. It is seen that the machine comprises numerous cylinder pressure chambers being radially distributed around an eccentric shaft. The flow to and from the 


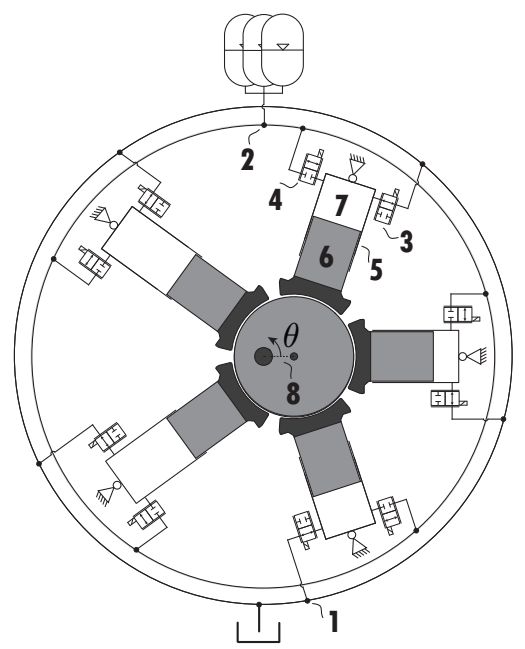

1 Low pressure mainfold

2 High pressure manifold

3 Low pressure valve

4 High pressure valve

5 Cylinder

6 Piston

7 Cylinder chamber (Pressure chamber)

8 Eccentric

Figure 1: Illustration of the radial piston type digital displacement machine with 5 cylinders.

pressure chambers is controlled by electro-magnetically actuated on/off valves connecting each pressure chamber to the high and low pressure manifold. A more detailed description of the digital displacement technology may be found in several publications Ehsan et al. (1997); Payne et al. (2005); Rampen (2010); Roemer (2014); Noergaard (2017); Johansen (2014); Johansen et al. (2015b).

Published state of the art control strategies for digital displacement units is mostly limited to neglecting the transient behavior of the machine and utilizing pulse density modulation or pulse width modulation techniques to determine the actuation sequence for the pressure chambers Johansen et al. (2015a); Sniegucki et al. (2013). Another method where the dynamics has been neglected is through determination of the actuation sequence of the individual chambers as function of the displacement reference and shaft angle through offline optimization Armstrong and Yuan (2006); Sniegucki et al. (2013); Song (2008); Heikkila and Linjama (2013). However, none of these methods includes the machine dynamics which may introduce transient problems with respect to stability and performance. Dynamical models applicable for system analysis and controller design has been developed and governs both continuous, discrete and hybrid representations Johansen et al. (2017); Pedersen et al. (2016b, 2017a,b,c, 2018c); Sniegucki et al. (2013). However, the discrete and continuous models are often only valid in limited situations, while the hybrid models are often quite complex with respect to development of stabilizing feedback control laws. This paper provides a clarification of the related control challenges in a broad range of machine operations, machine designs and possible target applications. A discussion of the applicable control models and methods, as well as their limitations is made. The findings of the paper should hence serve as a tool for determining suitable control strategies and dynamical control oriented models when utilizing digital displacement machines.

\section{Simplified model analysis}

Instead of deriving a complex model for investigation of the control challenges, a relatively simple model with idealized behavior is used. The model maintains all the system wide control challenges and includes the fundamental dynamics of the machine. Although only system wide control is considered in this paper, valve control related problems are important for proper machine operation. The non-linear features during the switching event has been studied in Bender et al. (2018b); Roemer et al. (2015a, 2014, 2013, 2015b) and the repetitive nature of the machine has lead to several valve timing control strategies Bender et al. (2018a); Brendi et al. (2017); Breidi (2016); Merrill (2012). The derivation of the mathematical model of the macro dynamics is based on the illustration of a single pressure chamber shown in Fig. 2.

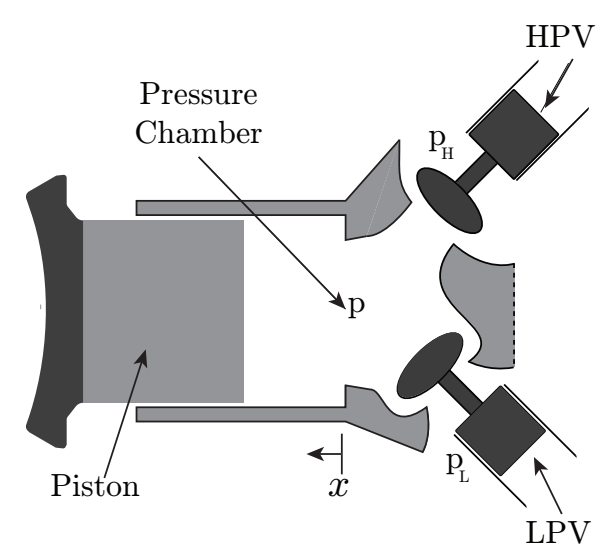

Figure 2: Illustration of the individual pressure chamber and the configuration of the corresponding valves.

It is seen that a normally closed high pressure valve (HPV) and a normally open low pressure valve (LVP) is used, such that each pressure chamber is normally in an idling mode at low pressure. The piston displacement, $x$, is kinematically described as function of the shaft angle given by

$$
x_{\mathrm{i}}\left(\theta_{\mathrm{i}}\right)=r_{\mathrm{e}}\left(1-\cos \left(\theta_{\mathrm{i}}\right)\right)
$$

where $r_{\mathrm{e}}$ is the eccentric radius, such that the piston stroke length is $\bar{x}=2 r_{\mathrm{e}}$. The local cylinder angle is 
given by

$$
\theta_{\mathrm{i}}=\theta+\frac{2 \pi}{N_{\mathrm{c}}} i \quad i \in\left\{0, \ldots, N_{\mathrm{c}}-1\right\}
$$

where $N_{\mathrm{c}}$ is the number of cylinders. The cylinder chamber volume, $V$, is then given as

$$
\begin{aligned}
& V_{\mathrm{i}}\left(\theta_{\mathrm{i}}\right)=\frac{V_{\mathrm{d}}}{2}\left(1-\cos \left(\theta_{\mathrm{i}}\right)\right)+V_{0} \\
& \dot{V}_{\mathrm{i}}(\theta)=\frac{V_{\mathrm{d}}}{2} \sin \left(\theta_{\mathrm{i}}\right) \dot{\theta}
\end{aligned}
$$

where $V_{0}$ is the minimum chamber volume and $V_{\mathrm{d}}=$ $2 r_{\mathrm{e}} A_{\mathrm{p}}$ is the displacement volume, with $A_{\mathrm{p}}$ being the piston area. The pressure dynamics in one displacement chamber is governed by the continuity equation and is given to be

$$
\dot{p}_{\mathrm{i}}=\frac{\beta_{\mathrm{e}}}{V_{\mathrm{i}}}\left(Q_{\mathrm{H}, \mathrm{i}}-Q_{\mathrm{L}, \mathrm{i}}-\dot{V}_{\mathrm{i}}\right)
$$

Where $Q_{\mathrm{H}}$ and $Q_{\mathrm{L}}$ are the flows through the high and low pressure valve respectively and $\beta_{\mathrm{e}}$ is the effective bulk modulus. The oil-flows through the valves may be described by the orifice equation given by

$$
\begin{aligned}
Q_{\mathrm{L}, \mathrm{i}} & =\frac{\bar{x}_{\mathrm{L}}}{k_{\mathrm{f}}} \sqrt{\left|p_{\mathrm{i}}-p_{\mathrm{L}}\right|} \operatorname{sign}\left(p_{\mathrm{i}}-p_{\mathrm{L}}\right) \\
Q_{\mathrm{H}, \mathrm{i}} & =\frac{\bar{x}_{\mathrm{H}}}{k_{\mathrm{f}}} \sqrt{\left|p_{\mathrm{H}}-p_{\mathrm{i}}\right|} \operatorname{sign}\left(p_{\mathrm{H}}-p_{\mathrm{i}}\right)
\end{aligned}
$$

where $k_{\mathrm{f}}$ is the valve flow coefficient and $\bar{x}_{\mathrm{L}}$ and $\bar{x}_{\mathrm{H}}$ are normalized valve plunger positions. The torque from each pressure chamber is described by

$$
\tau_{\mathrm{i}}=\frac{d V_{\mathrm{i}}\left(\theta_{\mathrm{i}}\right)}{d \theta} p_{\mathrm{i}}=\frac{V_{\mathrm{d}}}{2} \sin \left(\theta_{\mathrm{i}}\right) p_{\mathrm{i}}
$$

The dynamical behavior of a single pressure chamber is investigated by considering the pressure trajectories as function of the shaft angle in a polar phase plot shown in Fig. 3. In the simulation, the pressure is initially equal to the high pressure, $p=p_{\mathrm{H}}$, during the down-stroke, $\theta=[0 ; \pi]$ and the initially open HPV is closed $\bar{x}_{\mathrm{H}}: 1 \rightarrow 0$. This results in a depressurization and when $p<p_{\mathrm{L}}$ the LPV is passively opened $\bar{x}_{\mathrm{L}}: 0 \rightarrow 1$. During the upstroke, $\theta=[\pi ; 2 \pi]$, the pressure is initially equal to the low pressure $p=p_{\mathrm{L}}$ and the initially open LPV is closed $\bar{x}_{\mathrm{L}}: 1 \rightarrow 0$. This results in a pressurization and when $p>p_{\mathrm{H}}$ the HPV is passively opened $\bar{x}_{\mathrm{H}}: 0 \rightarrow 1$. $\phi_{\mathrm{mL}}$ is the latest angle that the LPV should be closed in order to obtain passive opening of the HPV at top dead center (TDC). $\phi_{\mathrm{mH}}$ is the latest angle that the HPV should be closed during motoring for the LPV to be passively opened at bottom dead center (BDC). Similarly, $\phi_{\mathrm{pL}}$ is the earliest angle that the pumping stroke may be initiated

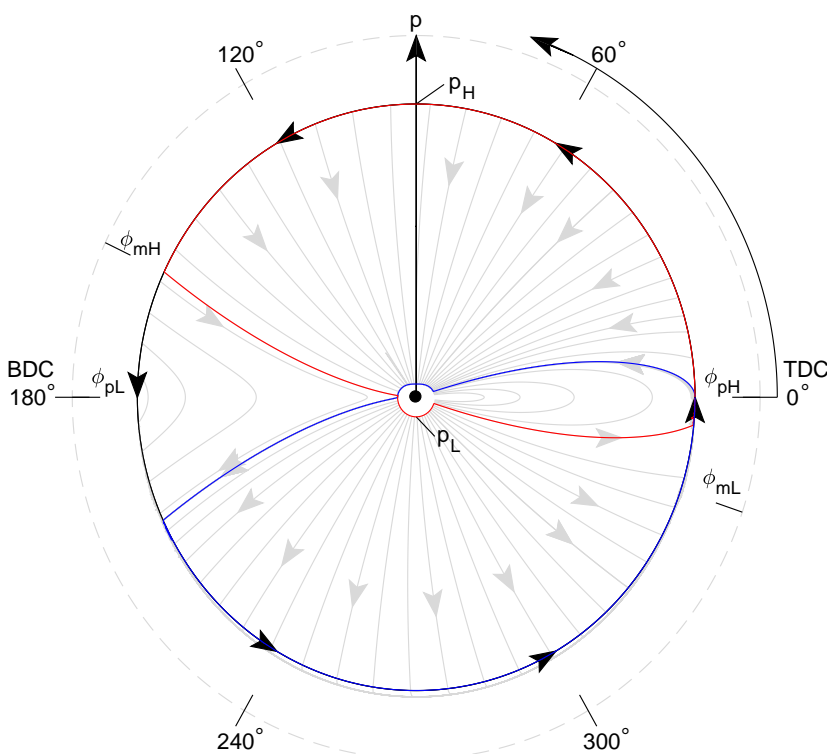

Figure 3: Phase portrait of the pressure dynamics as function of the angle. Red trajectory illustrates a full motoring stroke and blue trajectory illustrates a full pumping stroke.

and $\phi_{\mathrm{pH}}$ is the angle where the HPV is closed to end the pumping stroke.

It is seen that the pressurization and depressurization are very fast as function of the angle except at BDC and TDC. Since the pressure is approximately constant when the HPV is open, the flow throughput may be simplified to be $Q_{\mathrm{H}} \approx \dot{V}_{\mathrm{c}}$, seen from (4), when considering the macro dynamics of the system. From the above analysis, the flow and torque as functions of the displacement volume are given by

$$
\mathcal{D}(\theta)=\frac{V_{\mathrm{d}}}{2} \sin (\theta) \bar{x}_{\mathrm{H}} \quad Q_{\mathrm{H}}=\mathcal{D} \dot{\theta} \quad \tau=\mathcal{D} p
$$

where $\bar{x}_{\mathrm{H}}=\{0,1\}$ depending on whether the chamber is active or inactive. The displacement throughput is used in the following analysis to examine the operation principle and control challenges related to the digital displacement machine. The control challenges for fulland partial-stroke operation are vastly different, since the system behavior is changed based on the chosen operation strategy. Therefore, the control challenges for the two operation strategies are investigated separately.

\section{Control Challenges - Full stroke}

Considering a full stroke operated DDM, the inputs may be considered to be $u=\{1,0,-1\}$ corresponding to motoring, idling and pumping respectively. For every chamber the decision to either motor or idle is done 
once every revolution at $\phi_{\mathrm{mL}}$, while the decision to either pump or idle is done once every revolution at $\phi_{\mathrm{pL}}$. This angle dependent sampling yields an asynchronous sampling scheme for varying shaft speeds due to the relation

$$
d \theta=\omega(t) d t \leftrightarrow d t=\frac{1}{\omega(\theta)} d \theta
$$

An illustration of the sampling scheme in the position domain and time domain for an arbitrary variable speed DDM is illustrated in Fig. 4.

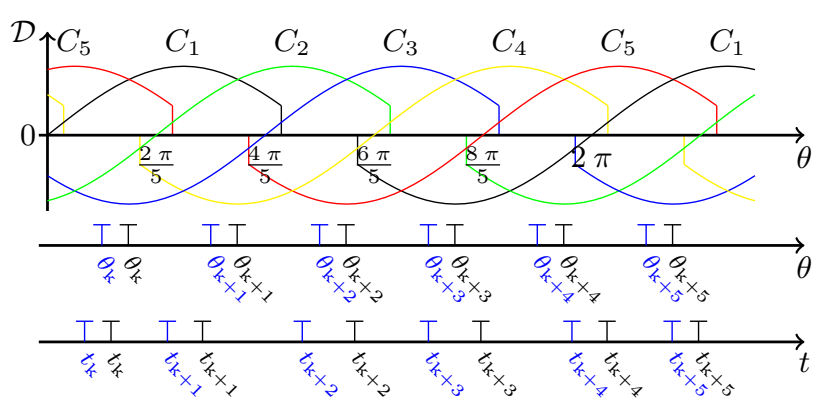

Figure 4: Displacement output response and control decision scheme of a full stroke operated DDM using both pumping and motoring strokes. Black samples are for motoring and blue samples are for pumping.

It is seen how a varying speed machine results in an asynchronous sampling scheme in the time domain, while the sampling scheme is synchronous in the angle domain if the machine is to only operate as a pump or motor. However, if the machine is to both motor and pump the sampling scheme is only periodic synchronous in the angle domain. Additionally, the inputs can only be chosen from $u_{\mathrm{m}}=\{1,0\}$ for motoring samples and $u_{\mathrm{p}}=\{0,-1\}$ for pumping samples, similar to a pulse density modulation technique used in electrical circuit control. Furthermore, the impulse response is seen to be different, since the last part of the motoring stroke is not used, while the first part of a pumping stroke is not used. Since a full stroke lasts for approximately half of a revolution, it takes half of a revolution to activate all the pressure chambers. Hence, the response angle from zero to maximum displacement is also half of a revolution. As a result, both the control input frequency and response time is proportional to the speed of the machine, while the displacement discretization resolution is proportional to the number of cylinders.

\subsection{Four quadrant operation}

An additional complication is introduced if the machine is to operate in both directions of motion, which may be illustrated by a steep change in the rotation speed between positive and negative rotation as shown in Fig. 5.

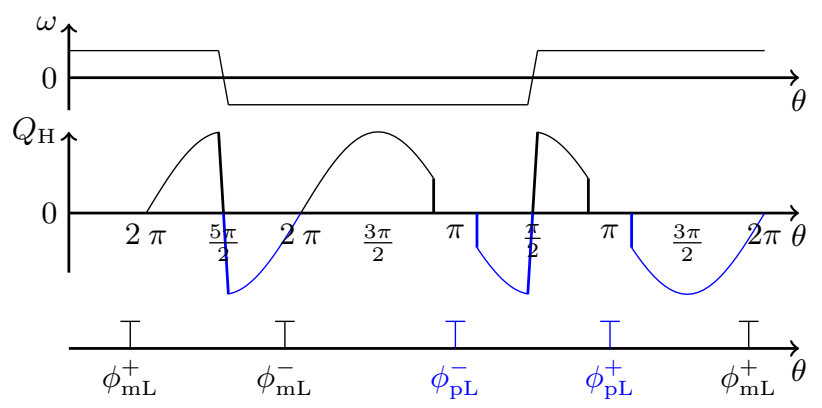

Figure 5: Illustration of response and sampling scheme with motion in both directions.

It is seen that a motoring decision is taken at $\phi_{\mathrm{mL}}^{+}$ ahead of TDC, but as the direction of motion is changed, the stroke becomes a pumping stroke. As a result, the subsequent decision is also for motoring, but since the direction of motion is reverse, the sampling angle ahead of TDC is now at $\phi_{\mathrm{mL}}^{-}=2 \pi-\phi_{\mathrm{mL}}^{+}$. The same is illustrated for a change of direction during a pumping stroke, which similarly results in two pumping samples subsequently. It is seen that the sampling scheme for a DDM operating in both directions is asynchronous in both the time and position domain and the position domain is further not monotonically increasing.

\section{Control Challenges - Partial stroke}

The challenges with respect to control of a partialstroke operated machine is very different than those identified for full-stroke operation. A partial motoring stroke is simply made by closing the HPV earlier and a partial pumping stroke by closing the LPV later as illustrated in Fig. 6.

It is seen that the impulse response of a partial stroke operated DD unit behaves different than that of a conventional dynamical system, since the input scales the width of the response rather than the amplitude. The input is the angle $\phi_{\mathrm{mH}}$ for motoring and $\phi_{\mathrm{pL}}$ for pumping, which controls the ratio where the given pressure chamber is active. The state changing input angle may be linearly normalized by an input variable change, such that the input is a displacement fraction $\eta=[0 ; 1]$. The input transformation is done by considering the committed displacement fraction for a motoring stroke 


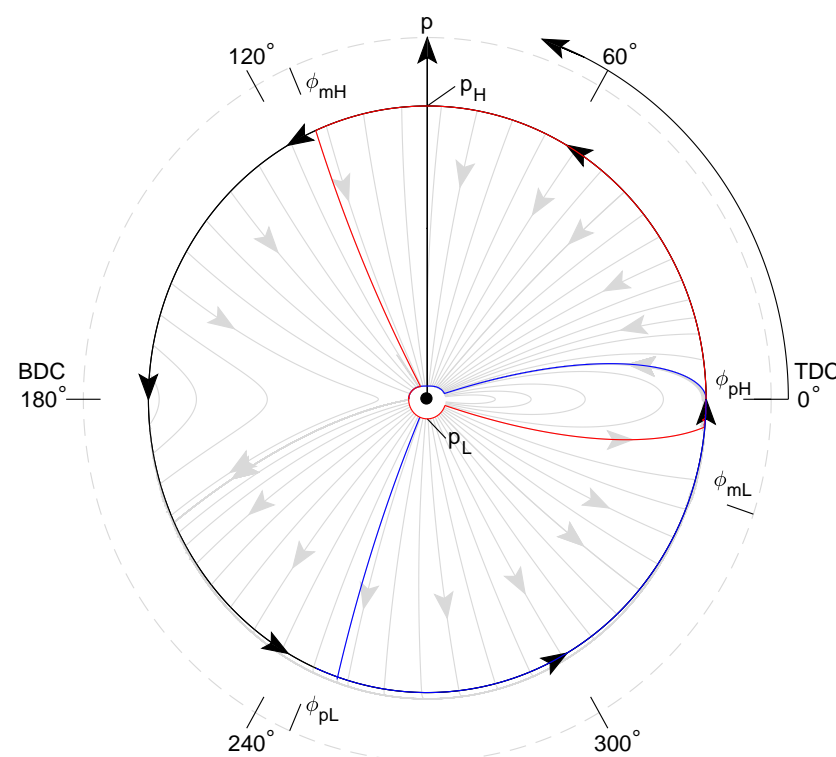

Figure 6: Phase portrait of the pressure dynamics as function of the angle. Red trajectory illustrates a $70 \%$ partial motoring stroke and blue trajectory illustrates a $70 \%$ partial pumping stroke.

by use of (3) and yields

$\eta_{\mathrm{m}}=\frac{V\left(\phi_{\mathrm{mH}}\right)}{V(\pi)}=\frac{\frac{V_{\mathrm{d}}}{2}\left(1-\cos \left(\phi_{\mathrm{mH}}\right)\right)}{\frac{V_{\mathrm{d}}}{2}(1-\cos (\pi))}=\frac{\left(1-\cos \left(\phi_{\mathrm{mH}}\right)\right)}{2}$

The resulting input transformation for motoring and pumping is then given by

$$
\begin{array}{rlrl}
\phi_{\mathrm{mH}}\left(\eta_{\mathrm{m}}\right) & =\operatorname{acos}\left(1-2 \eta_{\mathrm{m}}\right) & & \eta \in\left[0, \hat{\eta}_{\mathrm{m}}\right] \\
\phi_{\mathrm{pL}}\left(\eta_{\mathrm{p}}\right) & =2 \pi-\operatorname{acos}\left(1-2 \eta_{\mathrm{p}}\right) & \eta \in\left[0, \hat{\eta}_{\mathrm{p}}\right]
\end{array}
$$

where $\hat{\eta}_{\mathrm{m}}$ and $\hat{\eta}_{\mathrm{p}}$ are the maximum possible displacement fractions (corresponding to a full stroke) for motoring and pumping respectively. How the impulse response of the DD unit depends on the input is illustrated in Fig. 7 for a motoring stroke, where $\eta_{\mathrm{m}}=0.7$ corresponding to a displacement of $70 \%$ of the maximum displacement. It is seen that the state change of a chamber from active to inactive may only be given once for each revolution (considering motoring mode only) with conventional partial stroke. Therefore, the decision frequency is still proportional to the speed of the machine, but the response may be smoothened compared to full stroke operation. The state changing angle may however be updated continuously until the state change is carried out at the given angle. Considering, the input to be limited to only update at $\phi_{\mathrm{mL}}$, when the stroke is initiated, the system becomes a sample-and-hold system similar to that for

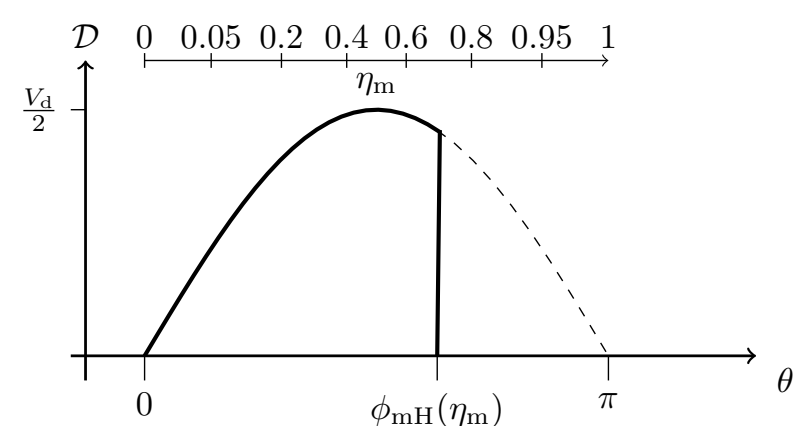

Figure 7: Impulse response as function of the input, $\eta_{\mathrm{m}}=0.7$ in conventional partial stroke operation.

full-stroke. However, the impulse response is now timevarying, where the number of subsequent samples being made during the length of the impulse response varies as function of the input. This is illustrated in Fig. 8, where it is shown that $50 \%$ displacement during one revolution may be obtained with vastly different activation patterns.
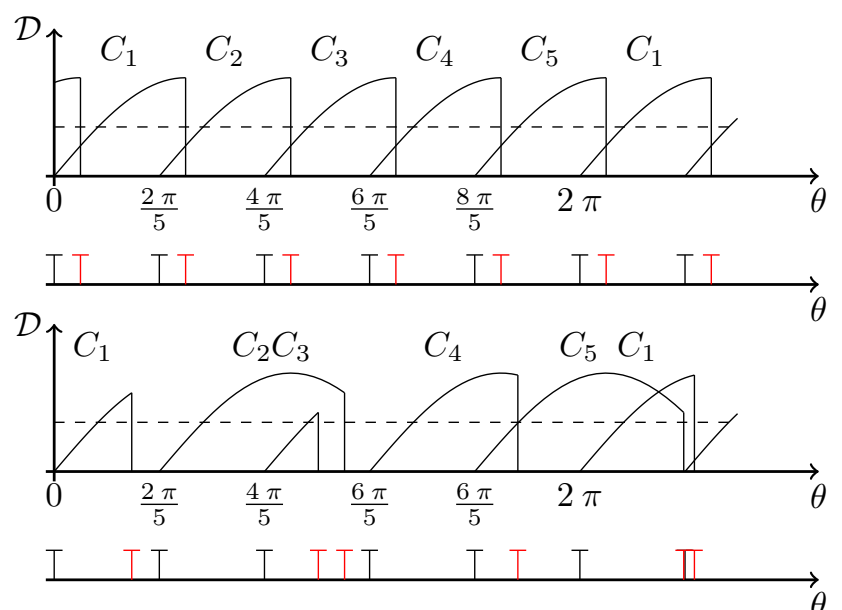

Figure 8: Flow/torque output response and control decision scheme of a partial stroke operated DDM, using only motoring strokes.

The top shown activation pattern corresponds to the output of a pulse width modulation strategy, while the bottom shown pattern is one arbitrary pattern of infinitely many, yielding an average of $50 \%$ displacement during a full revolution. Since the flow is highest at the mid-point between TDC and BDC, the most severe flow spikes are also expected to occur if the valves are switched here. The flow level also has an impact on the energy cost when switching, which however is minor since the pressure across the valve is low when switching. 


\subsection{Sequential partial stroke}

If the valves are designed to be able to open against high pressure difference, the sequential partial stroke method may be used to allow for multiple state changes during a revolution as illustrated in Fig. 9.

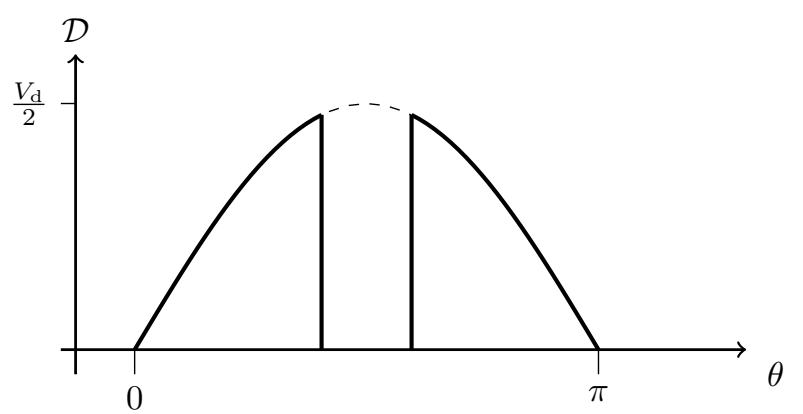

Figure 9: Impulse response as function of the input, $\eta_{\mathrm{m}}=0.7$, with sequential partial stroke.

It is seen that a $70 \%$ stroke has been split into two sections, but in theory the displacement may be split into many more parts. With sequential partial stroke it is also possible to utilize the last part of the motoring stroke and first part of a pumping stroke, since the valves may be actively opened and closed independent of the angle. With this strategy, the state changing input may be updated continuously and is only constrained by the time it takes to open and close the valves. Therefore, the response may become even more smooth with this strategy. However, opening the HPV against high pressure difference (against the solution trajectories shown in Fig. 6) requires a substantially amount of energy and larger valves with higher actuation power is necessary Noergaard (2017). Even though the input may be updated continuously it is still binary, such that the output is in discrete levels based on the shaft angle as shown in Fig. 10. Only

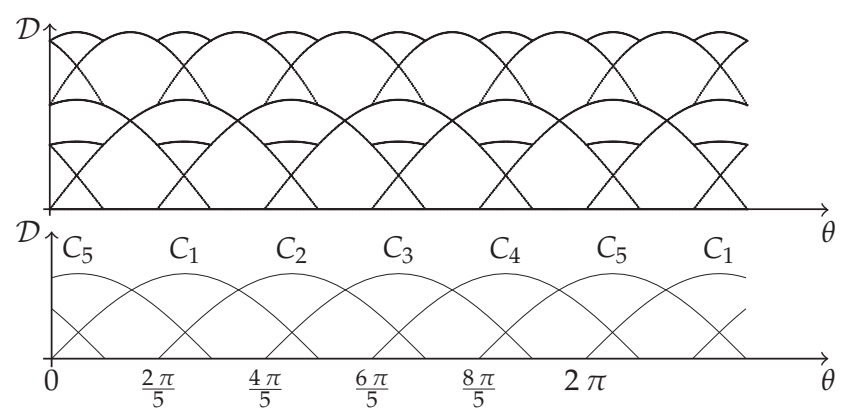

Figure 10: Illustration of the displacement combinations as function of the shaft angle with 5 cylinders. motoring combinations are illustrated, but the number of combinations may be increased by including the possibility to pump. This does however mean that several cylinders will work against each other to lower the combined throughput. Contrary to conventional discrete input systems, it is seen that the discrete levels are changing as function of the angle.

\subsection{Discussion of operation methods}

The investigation clearly identifies that the dynamical behavior and control complications of the digital displacement machine is greatly influenced by the chosen operation strategy. A summarization of the dynamical behavior and control challenges is provided in Tab. 1. To give an overview of when to use which operation strategy, based on the mentioned advantages and disadvantages the following may be summarized:

- Full stroke: Is considered the favorable choice for high-speed machine operation, where energy efficiency is important. Also it is considered the most simple strategy, since state changes are done at fixed angles.

- Partial stroke: Is considered the favorable choice for low-speed machine operation, where both tracking performance and energy efficiency is important.

- Sequential partial stroke: Is considered the favorable choice for very low-speed machine operation, where control tracking performance is important and energy efficiency is of less importance.

Even though the advantages and disadvantages of each method are speed dependent, it may also be beneficial to use a full stroke strategy at low speed if tracking performance is not very important, but simplicity and energy efficiency is. Similar, it may be beneficial to use a partial stroke strategy at high speed, if tracking performance is very important, but simplicity and energy efficiency is not.

Based on the above analysis it may be favorable to utilize a combination of full-stroke and partial-stroke operation if the machine is to operate in a wide range of speeds. However, a combination of full and partial stroke operation is simply a partial stroke operation, since a full stroke is also a possible choice when utilizing a partial stroke strategy. Using the sequential partial stroke strategy, where several state changes may be made during each stroke also covers the conventional partial stroke strategy, since a possible choice is to only do one state change or none at all (full stroke). This does however not mean that it is advantageous to use the sequential partial stroke independent of the operation speed and application, since the strategy requires 
Pedersen et.al., "Challenges with respect to Control of Digital Displacement Hydraulic Units"

\section{Machine features}

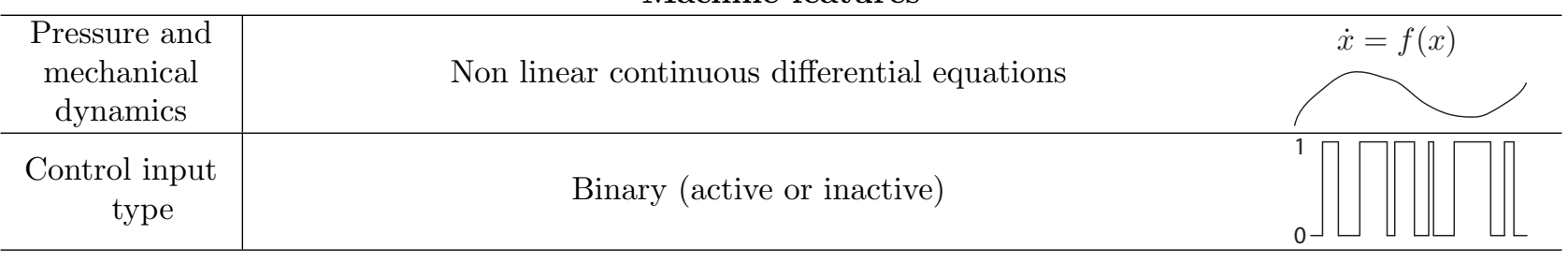

Operation strategy features

\begin{tabular}{|c|c|c|c|c|}
\hline & Full stroke & Partial Stroke & $\begin{array}{c}\text { Sequential Partial } \\
\text { stroke }\end{array}$ & \\
\hline $\begin{array}{l}\text { Valve type } \\
\text { and } \\
\text { requirements }\end{array}$ & $\begin{array}{l}\text { Only capable of } \\
\text { opening against low } \\
\text { pressure difference }\end{array}$ & $\begin{array}{l}\text { Only capable of } \\
\text { opening against low } \\
\text { pressure difference }\end{array}$ & $\begin{array}{c}\text { Capable of opening } \\
\text { against high pressure } \\
\text { difference }\end{array}$ & \begin{tabular}{l|l|l}
$u$ & $\uparrow$ & $\perp$ \\
$y$ & $\downarrow$ & $T$ \\
\end{tabular} \\
\hline $\begin{array}{c}\text { Control } \\
\text { update rate }\end{array}$ & $\begin{array}{l}\text { Proportional to the } \\
\text { shaft speed and once } \\
\text { every revolution at a } \\
\text { fixed angle for both } \\
\text { pumping and } \\
\text { motoring } \\
\end{array}$ & $\begin{array}{l}\text { Proportional to the } \\
\text { shaft speed and once } \\
\text { every revolution at a } \\
\text { variable angle for } \\
\text { both pumping and } \\
\text { motoring } \\
\end{array}$ & $\begin{array}{l}\text { Continuous, but } \\
\text { constrained by the } \\
\text { actuation time }\end{array}$ & 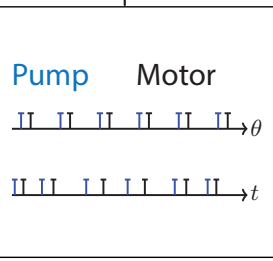 \\
\hline $\begin{array}{l}\text { Displacement } \\
\text { resolution }\end{array}$ & $\begin{array}{l}\text { Proportional to the } \\
\text { number of cylinders } \\
\text { over one revolution } \\
\text { and non-existent } \\
\text { instantaneously }\end{array}$ & $\begin{array}{l}\text { Continuous over one } \\
\text { revolution and } \\
\text { non-existent } \\
\text { instantaneously }\end{array}$ & $\begin{array}{l}\text { Continuous over one } \\
\text { revolution, but } \\
\text { proportional to the } \\
\text { number of cylinders } \\
\text { instantaneously with } \\
\text { discrete levels being } \\
\text { dependent on the } \\
\text { angle }\end{array}$ & ${ }^{D}$ \\
\hline $\begin{array}{l}\text { Chamber } \\
\text { impulse } \\
\text { response time }\end{array}$ & $\begin{array}{l}\text { Proportional to the } \\
\text { shaft speed (half of a } \\
\text { revolution) }\end{array}$ & $\begin{array}{l}\text { Scaled by the input, } \\
\text { up to half of a } \\
\text { revolution. The } \\
\text { impulse response } \\
\text { time is hence scaled } \\
\text { by the input and } \\
\text { shaft speed. }\end{array}$ & $\begin{array}{c}\text { The time between } \\
\text { each actuation } \\
\text { decision }\end{array}$ & \\
\hline $\begin{array}{l}\text { Machine } \\
\text { response time } \\
(0 \text { to max } \\
\text { displacement })\end{array}$ & $\begin{array}{l}\text { Proportional to the } \\
\text { shaft speed (half of a } \\
\text { revolution) }\end{array}$ & $\begin{array}{l}\text { Proportional to the } \\
\text { shaft speed (up to } \\
\text { half of a revolution) }\end{array}$ & $\begin{array}{l}\text { Instantaneously } \\
\text { (limited by the } \\
\text { actuation time) }\end{array}$ & \\
\hline $\begin{array}{l}\text { Pumping vs } \\
\text { motoring }\end{array}$ & $\begin{array}{l}\text { Impulse response is } \\
\text { different (first part of } \\
\text { pumping is not used } \\
\text { and last part of } \\
\text { motoring is not used) }\end{array}$ & $\begin{array}{l}\text { Impulse response is } \\
\text { different (first part of } \\
\text { pumping is not used } \\
\text { and last part of } \\
\text { motoring is not used) }\end{array}$ & Similarly & \\
\hline $\begin{array}{l}\text { Change of } \\
\text { rotation } \\
\text { direction }\end{array}$ & $\begin{array}{l}\text { Pumping becomes } \\
\text { motoring and vice } \\
\text { versa. Angle of } \\
\text { control decision } \\
\text { changes. }\end{array}$ & $\begin{array}{l}\text { Pumping becomes } \\
\text { motoring and vice } \\
\text { versa. Angle of } \\
\text { control decision } \\
\text { changes. }\end{array}$ & $\begin{array}{l}\text { Pumping becomes } \\
\text { motoring and vice } \\
\text { versa }\end{array}$ & \\
\hline $\begin{array}{l}\text { Energy cost } \\
\text { and pressure } \\
\text { spikes }\end{array}$ & $\begin{array}{l}\text { Very low due to no } \\
\text { pressure difference } \\
\text { across the valve and } \\
\text { no flow at switching }\end{array}$ & $\begin{array}{l}\text { Dependent on the } \\
\text { angle where the } \\
\text { chamber is } \\
\text { deactivated. Largest } \\
\text { at mid-point between } \\
\text { BDC and TDC }\end{array}$ & $\begin{array}{l}\text { Dependent on the } \\
\text { angle where the } \\
\text { chamber is } \\
\text { deactivated. Largest } \\
\text { at mid-point between } \\
\text { BDC and TDC. }\end{array}$ & \\
\hline
\end{tabular}

Table 1: Summarization of the dynamical behavior and control challenges of digital displacement units. 
large active valves capable of opening against high pressure and the control complexity may be severely increased if the optimal control choice is e.g. only full strokes.

\section{Control model development}

For successful deployment of the digital displacement machine in a wide range of application it is beneficial to be able to analyze and design feedback controllers independently of operation. This is considered a complex task, especially since the dynamics is changing significantly depending on operation. Instead of developing a very complex control oriented model capable of handling every situation, it is considered beneficial to develop control oriented models for specific situations individually. In certain situations, simple dynamical approximation models may be sufficient for describing the systems macro dynamics.

\subsection{Continuous approximation}

Even though the non-smooth dynamical system is discretely controlled, a continuous approximation may be applicable in certain situations and results in a significantly simpler model for analysis and control design Pedersen et al. (2018a). The continuous approximation is illustrated for a full stroke operated pulse-density modulated (PDM) machine and a partial stroke pulsewidth modulated (PWM) machine, where the input corresponds to a duty cycle. The step response for various duty cycles (normalized displacement fraction

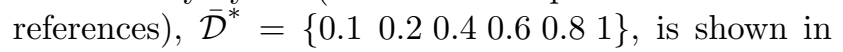
Fig. 11. Both responses for a machine with 5 cylinders and one with 20 cylinders is shown to illustrate the applicability of the method. It is seen that for a high number of pressure chambers, the response resembles a continuous response with ripples in the position domain. However, for low displacement fractions, the continuous approximation is seen to be quite poor for a full stroke PDM strategy, while it remains reasonably accurate with a partial stroke PWM strategy. The response may be fitted to a continuous transfer function by use of a spatial domain Laplace transformation defined as

$$
F(\bar{s})=\mathcal{L}\{f(\theta)\}=\int_{0}^{\infty} e^{-\bar{s} \theta} f(\theta) d \theta
$$

Fitting the response dynamics to a second order system results in the transfer function given by

$$
G(\bar{s})=\frac{\mathcal{D}}{\mathcal{D}^{*}}=K \frac{\omega_{\mathrm{n}}^{2}}{\bar{s}^{2}+2 \zeta \omega_{\mathrm{n}} \bar{s}+\omega_{\mathrm{n}}^{2}} e^{-\bar{s} \theta_{\mathrm{d}}}
$$
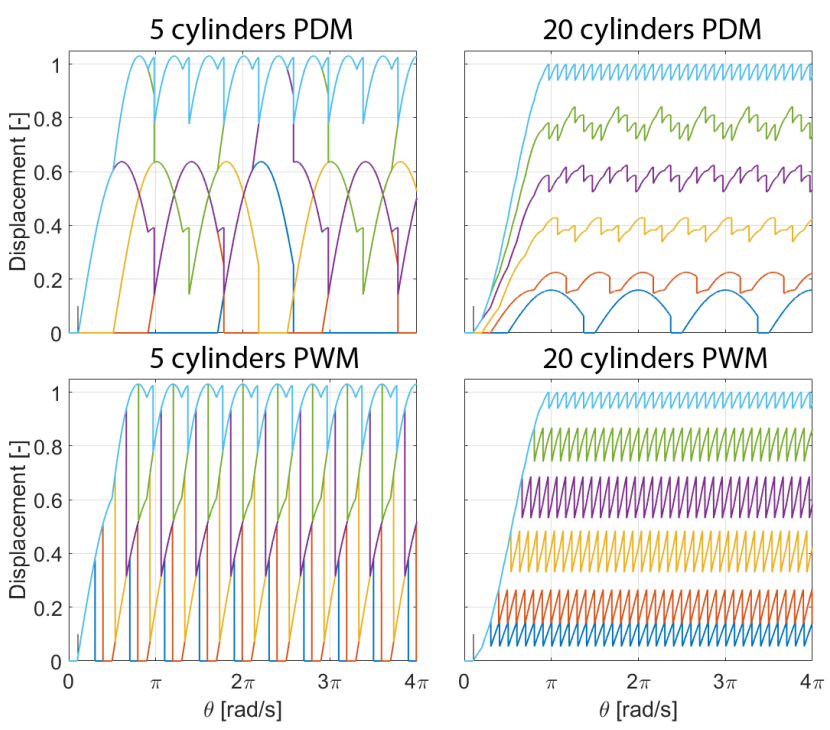

Figure 11: Step response for various displacements using delta-sigma modulation and pulsedensity modulation.

where $\theta_{\mathrm{d}}$ is the delay angle due to the decision being made ahead at $\phi_{\mathrm{mL}}$ ahead of TDC, where the active motoring stroke starts. Converting the transfer function to the time domain by (8) yields a time-invariant system dependent on the machine speed. Therefore, if linear control is to be applied, a linearization point for the shaft speed must be chosen. In the time domain the bandwidth of the system is proportional to the shaft speed and to ensure stability in the case of linear control, the speed should be greater than the linearization speed. For high speed operation the dynamics of the machine is possibly significantly faster than the dynamics of the high pressure line and mechanical system it is connected to and may therefore possibly be neglected during control design. This is coherent with the non-smooth ripples in the response not being seen in the mechanical response for high mass inertia systems. It should however be clear that the method is very inaccurate for a low number of cylinders and for full stroke operation also at low displacements, where this method should not be applied. It is also important to consider that it is a discrete sampled system, so a continuous approximation is only valid up to a certain frequency where the sampling effect becomes significant.

\subsection{Discrete approximation}

To capture the discrete control effect of a full stroke operated digital displacement machine, a discrete approximation of the machine dynamics may be applied in several situations Johansen et al. (2017); Pedersen 
et al. (2017a,b, 2018d). The displacement throughput between samples is given by the change in chamber volume divided by the constant sampling angle given as

$$
\Delta \mathcal{D}[k]=\frac{\Delta V[k]}{\theta_{\mathrm{s}}}=\frac{(V[k+1]-V[k]) N}{2 \pi}
$$

where $\theta_{\mathrm{s}}$ is the sampling angle and $\mathrm{N}$ is the number of cylinders. The discrete approximation of the displacement response is shown in Fig. 12 for a DDM with 15 cylinders.

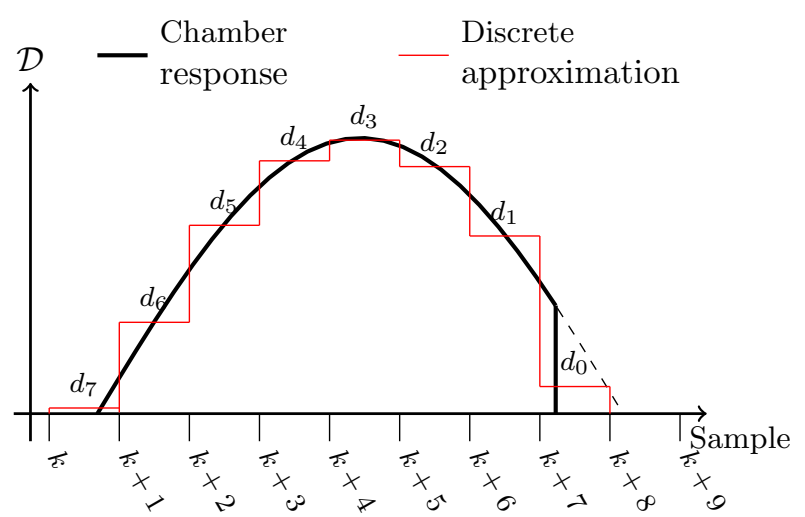

Figure 12: Discretization of displacement response for a motoring stroke.

The discrete response is seen to be fairly accurate for a high number of cylinders. The initial delay is again due to the decision being taking at $\phi_{\mathrm{mL}}$ ahead of TDC. The discrete transfer function becomes that given by

$$
G(z)=\frac{\mathcal{D}}{u}=\frac{d_{7} z^{7}+d_{6} z^{6}+\cdots+d_{1} z+d_{0}}{z^{7}}
$$

where $u=\{0,1\}$ depending on whether an active or inactive stroke is taken. Utilizing a pulse density modulator introduces a high non-linearity to the control system due to the quantizer given by

$$
u[k]=\left\{\begin{array}{lll}
1 & \text { if } & \overline{\mathcal{D}}^{*}[k] \geq 0.5 \\
0 & \text { if } & \overline{\mathcal{D}}^{*}[k]<0.5
\end{array}\right.
$$

where $\overline{\mathcal{D}}^{*}[k]$ is the displacement fraction reference. Since the flow and torque are functions of the speed and pressure respectively given by (7), the output transfer function is non-linear. Additionally, for a variable speed machine the sampling scheme is asynchronous, why a transformation to the position domain by (17) is necessary to obtain a synchronous sampled system.

$$
\frac{d x}{d \theta}=\frac{1}{\omega(\theta)} \frac{d x}{d t}
$$

However, this transformation is seen to yield another non-linearity due to the speed being varying. Since non-linear discrete control is often quite complex, simpler linear approximations are often applied, which however limit the range of applicability. By linearizing around a steady-state speed, the operation speed should be greater than the linearization speed to ensure stability. The common method of describing a quantizer linearly is to simply consider the quantizer as an additive noise input, $u[k]=\overline{\mathcal{D}}^{*}[k]+n[k]$. This corresponds to a duty-cycle ratio approximation, where $n[k]$ is the noise input with intensity $I \in[0 ; 0.5]$. By omitting the noise term, the resulting response is shown in Fig. 13 for an input of $\overline{\mathcal{D}}^{*}[k]=1 / 3$. The discretization is not shown for simplicity of illustration.

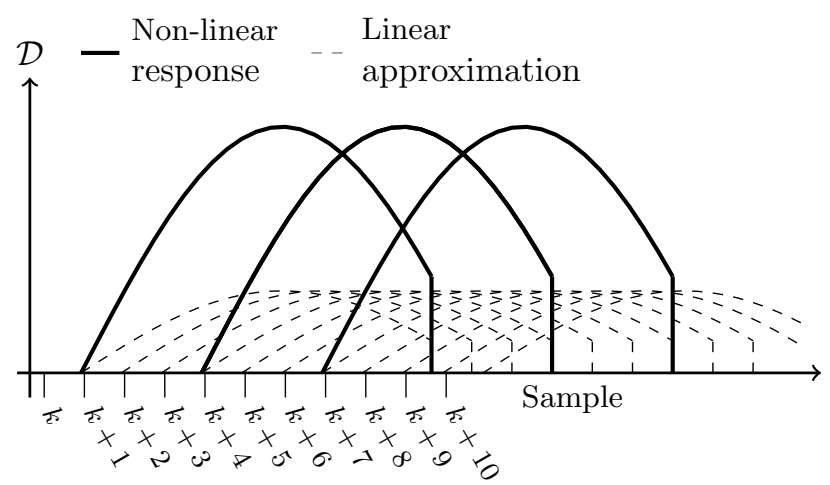

Figure 13: Discretization of displacement response.

It is seen that the linear approximation results in an angle average approximation, which is significantly more smooth than the non-linear physical response. Since the linear discrete approximation is poor at low displacement, it is not very accurate if the machine should both pump and motor. Furthermore, the pumping and motoring impulse responses are different, and if the method should both allow for pumping and motoring, synchronous sampling is required, which introduces additional delay to the system. The linear method hence includes the sampling effect and to some extent the ripples in the response, but the method range of validity is limited to machines with a high number of cylinders and high displacements, similar to the continuous approximation. Additionally, the direction of motion must not change since a monotonically increase in the sampling domain (angle or time) is required when applying discrete control methods.

\subsubsection{Partial stroke strategy}

It has been identified that partial stroke and sequential partial stroke methods are great for low speed operation, where tracking performance is quite poor for a full stroke strategy. However, for a partial stroke op- 
eration, the energy cost of switching and the resulting pressure spikes are greatly influenced by the angle where the active stroke is stopped. With respect to control, the optimal solution may include trajectory tracking, energy efficiency, pressure spikes and frequency content, which is hardly achieved with a static control law. Therefore, model predictive control (MPC) is considered to have a high potential for control of a partial stroke operated DDM. MPC does however require a discrete model representation of the system dynamics Sniegucki et al. (2013); Pedersen et al. (2018c). For partial stroke operation, only a part of the full stroke is used, which introduces additional complications seen from a partial stroke discrete approximation shown in Fig. 14.

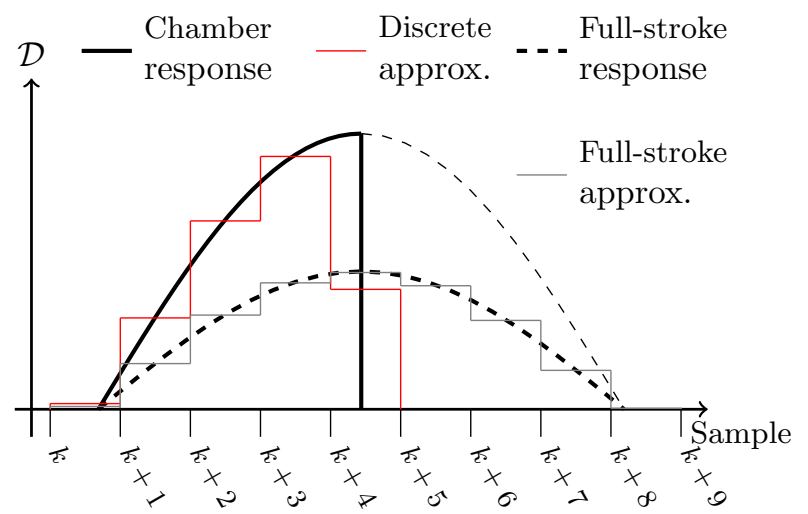

Figure 14: Discretization of displacement response, where $\eta=0.5$ corresponding to half of a stroke. A full stroke $\eta=1$, with $u=$ 0.5 yields the angle average committed displacement as if $\eta=0.5$ and $u=1$.

In this partial stroke example, the displacement is seen to be committed over less samples, such that the transfer function order is reduced to

$$
G(z)=\frac{\mathcal{D}}{u}=\frac{d_{4} z^{4}+d_{3} z^{3}+\cdots+d_{1} z+d_{0}}{z^{4}}
$$

Partial stroke operation hence results in an input dependent time-variant system, where the input to the transfer function is unity. This model is only obtainable if the stroke ratio is determined at sample $k$, where the stroke is initiated. If the stroke ratio may be updated continuously until the pressure chamber is deactivated, the impulse response and hence the discrete model is unknown when the stroke is initiated by closing the LPV at $\phi_{\mathrm{mH}}$. It is possible to apply model predictive control to such system, but it does not fulfill the requirements of classical MPC, where the input scales the magnitude of the response and not the model it self. To enable classical linear MPC control, an angle average approximation may me made, since a $50 \%$ stroke, $\eta=0.5$ with unity input, $u=1$, has the same integrated displacement as a full stroke, $\eta=1$, with input $u=0.5$. This angle average approximation is also shown in Fig. 14 and is seen to smoothen the response and be decreasingly accurate for lower displacement fractions. However, the angle average approximation is quite conservative with respect to stability, since the slowest response with the largest phase angle is a full stroke (highest order model), but the gain is seen to be lowered simultaneously. It should be evident, that for a fixed sampling angle, the time between samples is inverse proportional to the machine speed and to solve the optimization problem in real time constrains the maximum speed.

Similarly to partial stroke operation, MPC has a high potential for sequential partial stroke operation, since energy efficiency and pressure ripples become increasingly important with an increased number of switchings. MPC for a sequential partial stroke operated DDM is very similar to conventional MPC control of continuous dynamical systems, since the input may be updated at every sample Pedersen et al. (2018e). However, the input is limited to be a discrete set of displacements, which requires optimization algorithms capable of handling such problem. The methods enable both motoring and pumping strokes, since the optimal combination of all combinations of active and inactive pressure chambers is considered. The method does however not allow for operation in both directions, since the sampling domain must increase monotonically.

\subsection{Hybrid dynamical system}

Since the non-smooth dynamics of the digital displacement machine is of hybrid nature, hybrid system theory is able to describe both the continuous and discrete dynamics of the system Pedersen et al. (2017c, 2018b); Sniegucki et al. (2013). Neither continuous nor discrete approximations are able to describe the machine dynamics if the machine is to operate in both directions. Therefore, hybrid dynamical system theory is necessary to capture the dynamics, especially since stability is of high concern at low speeds where the control update rate is low in full and partial stroke operation. Furthermore, the approximation methods have shown poor accuracy for a low number of cylinders, low displacements and low speeds, where hybrid theory might be necessary to ensure stability and obtain the desired transient behavior. Several hybrid formulations exist, which are able to describe the dynamical behavior (e.g. hybrid automaton, impulsive system, switched system), where each has their own advantages and disadvantages. Although, hybrid dynamical sys- 
tem models are very intuitive, hybrid control theory is quite complex even for simple systems. Since a discrete event occurs every time a valve is opened or closed (or every time the pressure chamber is activated or deactivated) for every cylinder, the hybrid dynamical model of the digital displacement machine is not considered a simple system. Control theory for hybrid systems is an undergoing research topic, but stabilizing feedback control theory does exist, e.g. control Lyapunov function theory Teel et al. (2015); Goebel et al. (2009); Brogliato (2016).

\section{Control challenges related to application and design}

The control challenges when operating a system comprising digital displacement machines is highly dependent on the application where it is used. Furthermore, due to the modular construction of the machine, the control challenges are also greatly dependent on how the machine is designed and how it is connected to the individual target application.

\subsection{Fluid Power Transmission}

One application with very high potential for use of DDM's is a transmission system for converting low speed high torque power into high speed low torque power or vice versa. An illustration of a digital fluid power transmission is shown in Fig. 15. A ring cam design is used to increase the number of strokes per revolution of the slow rotating machine.

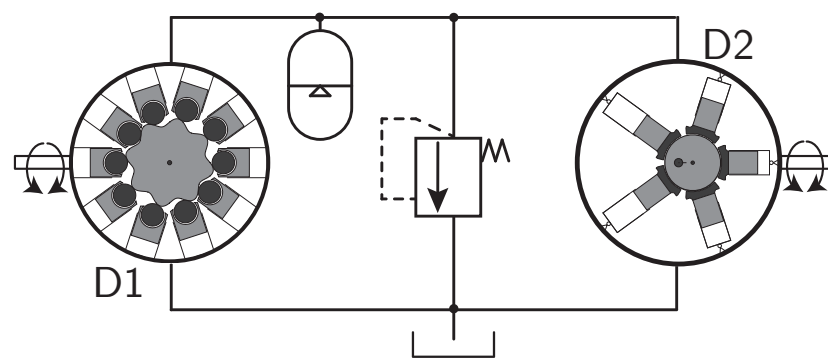

Figure 15: Illustration of a fluid power transmission system comprising two digital displacement machines.

Having multiple digital displacement machines which dynamics are directly influencing each other, the control challenges are further complicated. The high speed machine is seen to have 5 cylinders and the low speed machine to have 10 cylinders and 8 cam ring lobes for a total of 80 strokes per revolution. This means that for two digital displacement machines, where one is solely pumping and the other is solely motoring in a full stroke mode, the combined control input scheme is only periodic synchronous in the position domain even for fixed speed as illustrated in Fig. 16.

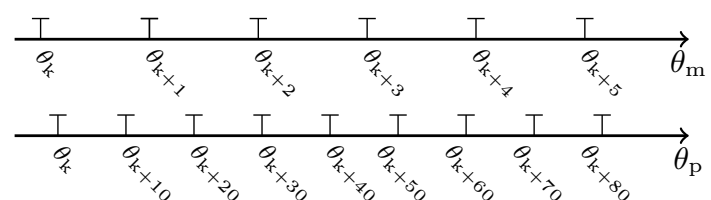

Figure 16: Input decision scheme for a digital hydraulic transmission with a high and a low speed digital displacement machine.

It is seen that if the number of strokes per revolution of the two machines are vastly different, a large amount of information is required to describe the combined sampling scheme in one revolution. Several drive trains need to operate in four quadrants, where each machine can both pump and motor and rotate in both directions (vehicle transmission etc.). Based on the identified control complications, it is clear that the control challenges of such system become significantly more complex and increasingly complicated if it is to utilize partial stroke operation also.

\subsection{Direct cylinder drive}

Another application where digital displacement machines has a large potential is in direct cylinder drives for large inertia systems, since they may potentially increase the energy efficiency significantly. A conceptional illustration of a multiple direct hydraulic cylinder drive is shown in Fig. 17.

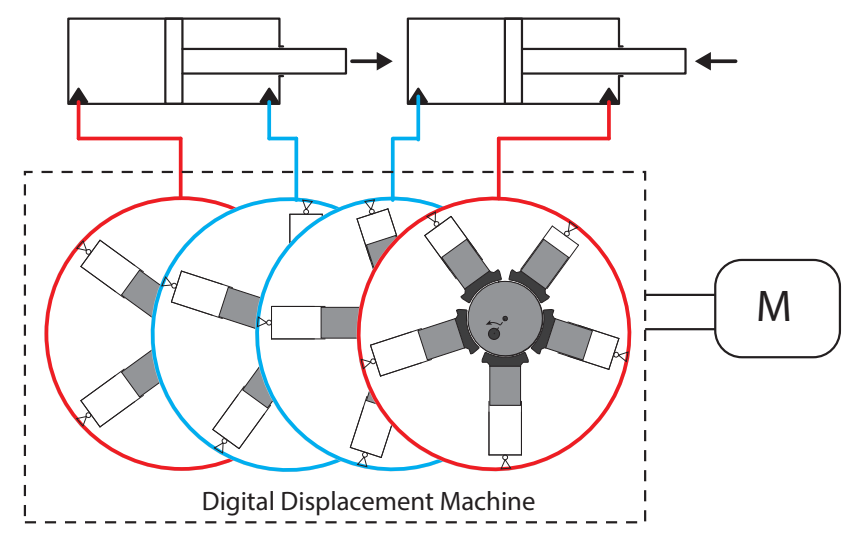

Figure 17: Conceptional drawing of a multiple cylinder digital displacement direct cylinder drive.

It is seen that one digital displacement machine is being powered by a motor and is used to control several hydraulic cylinders independently. In the illustrated concept, each module of the DDM is connected 
to either the rod or piston side of a cylinder for separate metering control. Development of a dynamic model allowing for analysis and control of such system is complicated, since the dynamics of the whole system is coupled through the mechanical shaft. Since the input for each main cylinder chamber may only be updated every fourth sample, the sampling scheme is again asynchronous. In theory, the connections between the chambers of the digital hydraulic machine and the main cylinder chamber could be reconfigured in many different combinations (e.g. connecting additional chambers to a main cylinder with a high load), which would change the dynamical behavior.

\subsection{Alternative machine design concepts}

An alternative concept is to utilize multiple independent inlets/outlets for each pressure chamber, requiring additional high pressure valves. The concept is similar to the digital hydraulic power management system (DHPMS) developed by Heikkila and Linjama (2013). This concept directly increases the control update rate for each input to the main cylinder chambers and thereby possibly improves the control performance. The multiple inlet/outlet digital hydraulic cylinder drive concept is illustrated in Fig. 18.
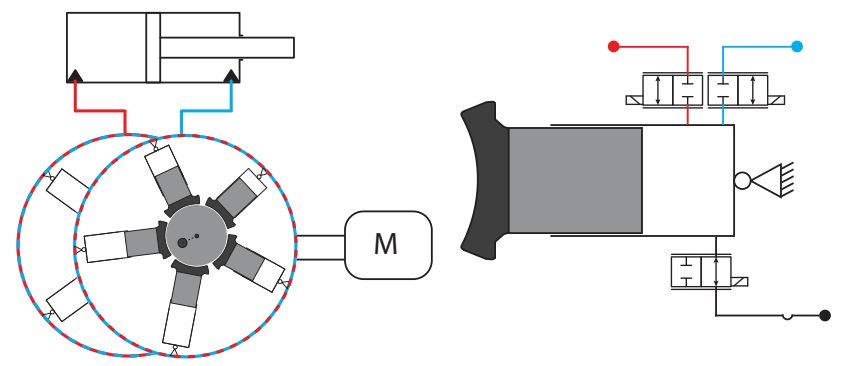

Figure 18: Conceptional drawing of a digital hydraulic direct cylinder drive with multiple inlets/outlets.

Even though the control update rate is doubled, the effective update rate is not, since multiple high pressure valves should not be opened simultaneously. This would result in a short circuit where the pressure is not controllable due to the differential cylinder and will thus lead to unwanted dynamical problems. With this concept the control input consists of multiple decisions, being pump to rod or piston or idle during up-stroke and motor to either piston or rod side or idle during down-stroke. Taking multiple decision is considered to further increase the control complexity, where classical discrete and continuous methods are not applicable.
With respect to control tracking performance, a high number of small cylinder chambers is beneficial, but it is much more costly than using a few larger cylinders. An alternative design that may be beneficial is to utilize multiple sized cylinders. Using such design with a full stroke operation strategy, the displacement discretization resolution is significantly improved without a huge increase in production cost. An illustration of a DDM with variable sized displacement chambers and its corresponding sampling scheme and impulse responses for motoring strokes is shown in Fig. 19.
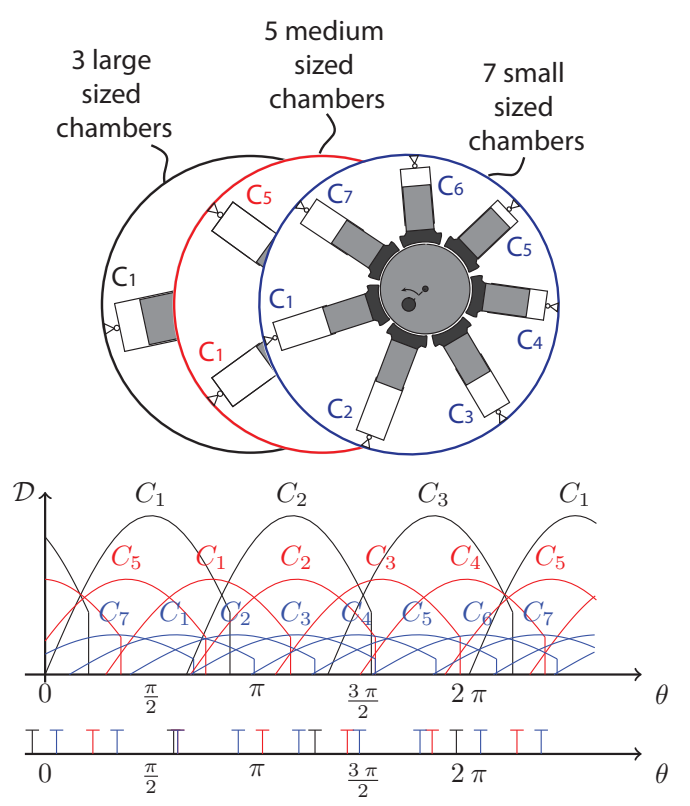

Figure 19: Illustration of a DDM with variable sized displacement chambers.

It is seen that the control update scheme is only periodic synchronous in the angle domain, while the impulse response is time varying dependent on the size of the chamber. As a result, this alternative concept introduces further complications with respect to model based dynamical analysis and control. Combining the different concepts: e.g. a multiple digital hydraulic direct cylinder drive with multiple sized displacement chambers and multiple inlets/outlets makes the dynamical control challenges tremendous, especially if it is to operate in all four quadrants and using both partial and full stroke methods.

To summarize the outcome of the investigation, it is identified that the control challenges and complexity is highly dependent on the machine configuration, operation strategy and the application it is used in. For the more complex systems, hybrid dynamical theory is considered necessary, but the development of stabilizing feedback control laws is very challenging and 
remains an undergoing research topic.

\section{Conclusion}

This paper identifies many of the challenges related to model based feedback control of digital displacement machines. It is found that the challenges are highly dependent on the chosen operation strategy of the machine, as well as how the machine is configured and in which application it is used. Since the continuous dynamics of each pressure chamber is activated or deactivated discretely, the system dynamics belongs to the class of hybrid systems. Since control of hybrid dynamical systems is quite complex and remains an active research field, simpler continuous and discrete approximations have been investigated and deemed valid in certain situations. However, to be able to perform proper feedback stabilizing control and obtain the desired transient performance in a broad range of situations, more advanced control theory is required, e.g. hybrid control. The paper hence provides an overview of the many unsolved problems related to control of digital displacement machines, which is considered a key elements for successful deployment of the technology in a broad range of hydraulic applications.

\section{Acknowledgments}

This research was funded by the Danish Council for Strategic Research through the HyDrive project at Aalborg University, at the Department of Energy Technology (case no. 1305-00038B). The work is made in cooperation with the research council of Norway, SFI offshore mechatronics, project number 237896/O30.

\section{References}

Armstrong, B. S. R. and Yuan, Q. Multi-level control of hydraulic gerotor motors and pumps. Proceedings of the american control conference, Minnesota, USA, 2006. doi:10.1109/ACC.2006.1657450.

Bender, N. C., Pedersen, H. C., and Andersen, T. O. Multiagent evolution algorithm for control of a repetitive non-linear dynamic system. Submitted to the ASME/BATH Symposium on Fluid Power and Motion Control, Bath, UK, 2018a.

Bender, N. C., Pedersen, H. C., Winkler, B., and Plckinger, A. Modeling transient flow phenomena in hydraulic seat valve with annular flow geometry. Submitted to the International Journal Fluid Power, 2018b.
Breidi, F. E. Investigation of digital pump/motor control strategies. Ph.D. thesis, Purdue University, West Lafayette, 2016. URL http://docs.lib.purdue. edu/open_access_dissertations/752.

Brendi, F., Garrity, J., and Lumkes, J. Investigation of a real-time pressure based valve timing correction algorithm. Proceedings of the ASME/BATH Symposium on Fluid Power and Motion Control, 2017. doi:10.1115/FPMC2017-4342.

Brogliato, B. Nonsmooth Mechanics - Models, Dynamics and Control (third edition). Springer, ISBN: 9781-4471-0557-2, 2016.

Ehsan, M., Rampen, W., and Salter, S. Modeling of digital-displacement pump-motors and their application as hydraulic drives for nonuniform loads. ASME. J. Dyn. Sys., Meas., Control., 1997. doi:10.1115/1.482444.

Goebel, R., Sanfelice, R. G., and Teel, A. R. Hybrid dynamical systems. IEEE Control Systems Magazine, Vol. 29, Iss. 2, pp. 28-93, 2009. doi:10.1109/MCS.2008.931718.

Hansen, A. H. and Pedersen, H. C. Optimal configuration of a discrete fluid power force system utilised in the PTO for WECs. Ocean Engineering, 2016. doi:10.1016/j.oceaneng.2016.03.032.

Hansen, R. H., Andersen, T. O., Pedersen, H. C., and Hansen, A. H. Control of a $420 \mathrm{kN}$ Discrete Displacement Cylinder Drive for the Wavestar Wave Energy Converter. In ASME/BATH 2014 Symposium on Fluid Power and Motion Control. 2014. doi:10.1115/FPMC2014-7833.

Heikkila, M. and Linjama, M. Displacement control of a mobile crane using digital hydraulic power management system. Mechatronics Volume 23, Issue 4, Pages 452-461, 2013. doi:10.1016/j.mechatronics.2013.03.009.

Jarf, A., Minav, T., and Pietola, M. Nonsymmetrical flow compensation using hydraulic accumulator in direct driven differential cylinder application. Proceedings of the 9th FPNI Ph.D. Symposium on Fluid Power, Florianpolis, Brazil, 2016. doi:10.1115/FPNI2016-1516.

Johansen, P. Tribodynamic Modeling of Digital Fluid Power Motors. Ph.D. thesis, Energy Technology, Aalborg University, Denmark, 2014.

Johansen, P., Roemer, D. B., Andersen, T. O., and Pedersen, H. C. Delta-sigma modulated displacement of a digital fluid power pump. The 7th workshop on digital fluid power, Linz, Austria, 2015a. 
Johansen, P., Roemer, D. B., Andersen, T. O., and Pedersen, H. C. On the Influence of Piston and Cylinder Density in Tribodynamics of a Radial Piston Digital Fluid Power Displacement Motor. In ASME/BATH 2015 Symposium on Fluid Power and Motion Control. 2015b. doi:10.1115/FPMC20159608.

Johansen, P., Roemer, D. B., Pedersen, H. C., and Andersen, T. O. Discrete linear time invariant analysis of digital fluid power pump flow control. Journal of Dynamic Systems, Measurement and Control, Transactions of the ASME, Vol. 139, 2017. doi:10.1115/1.4036554.

Merrill, K. J. Modeling and analysis of active valve control of a digital pump-motor. Ph.D. thesis, Purdue University, West Lafayette, 2012. URL https://docs.lib.purdue.edu/dissertations/ AAI3544301.

Noergaard, C. Design, Optimization and Testing of Valves for Digital Displacement $\mathrm{Ma}$ chines. Ph.D. thesis, Department of Energy Technology, Aalborg University, Denmark, 2017. doi:10.5278/vbn.phd.eng.00013.

Payne, G. S., Kiprakis, A. E., Ehsan, M., Rampen, W., Chick, J. P., and Wallace, A. R. Efficiency and dynamic performance of digital displacement hydraulic transmission in tidal current energy converters. Journal of Power and Energy, Proc. IMechE, Vol. 221, Part A, pp. 207-218., 2007. doi:10.1243/09576509JPE298.

Payne, G. S., Stein, U. P. P., Ehsan, M., Caldwell, N. J., and Rampen, W. H. S. Potential of digital displacement hydraulics for wave energy conversion. In Proc. of the 6th European Wave and TIdal Energy Conference, Glasgow UK., 2005.

Pedersen, H. C., Hansen, R. H., Hansen, A. H., Andersen, T. O., and Bech, M. M. Design of full scale wave simulator for testing power take off systems for wave energy converters. International Journal of Marine Energy, Vol. 13, pp. 130-156, 2016a. doi:10.1016/j.ijome.2016.01.005.

Pedersen, N. H., Johansen, P., and Andersen, T. O. Lqr feedback control development for wind turbines featuring a digital fluid power transmission system. Proceedings of the 9th FPNI Ph.D. Symposium on Fluid Power. American Society of Mechanical Engineers, 2016b. doi:10.1115/FPNI2016-1537.

Pedersen, N. H., Johansen, P., and Andersen, T. O. Event-driven control of a speed varying digital displacement machine. Proceedings of the 2017 Bath/ASME Symposium on Fluid Power and Motion Control, 2017a. doi:10.1115/FPMC2017-4260.

Pedersen, N. H., Johansen, P., and Andersen, T. O. Optimal control of a wind turbine with digital fluid power transmission. Nonlinear Dyn. 91: 591, 2017b. doi:10.1007/s11071-017-3896-0.

Pedersen, N. H., Johansen, P., and Andersen, T. O. Feedback control of multi-level pulse-density modulated digital displacement transmission. Submitted to IEEE/ASME Transaction on Mecatronics, 2018a.

Pedersen, N. H., Johansen, P., and Andersen, T. O. Four quadrant hybrid control oriented dynamical system model of digital displacement units. Submitted to the 2018 Bath/ASME Symposium on Fluid Power and Motion Control, 2018b.

Pedersen, N. H., Johansen, P., and Andersen, T. O. Model predictive control and discrete analysis of partial stroke operated digital displacement machine. Submitted to the Global Fluid Power Society PhD Symposium, 2018c.

Pedersen, N. H., Johansen, P., Andersen, T. O., and Scheidl, R. Non-linear hybrid control oriented modelling of a digital displacement machine. The Ninth Workshop on Digital Fluid Power, September 7-8, Aalborg, Denmark, 2017c.

Pedersen, N. H., Johansen, P., Andersen, T. O., and Scheidl, R. Discrete optimal control and potential analysis of a digital direct hydraulic cylinder drive. Submitted to Elsevier Journal of Mechatronics, 2018d.

Pedersen, N. H., Johansen, P., Hansen, A. H., and Andersen, T. O. Model predictive control of low-speed partial stroke operated digital displacement pump unit. Submitted to Journal of Model, Identification and Control, 2018e.

Rampen, W. Gearless transmissions for large wind turbines the history and future of hydraulic drives. Bremen, 2006.

Rampen, W. The development of digital displacement technology. In Proceedings of Bath/ASME FPMC Symposium, 2010.

Roemer, D. B. Design and Optimization of Fast Switching Valves for Large Scale Digital Hydraulic Motors. Ph.D. thesis, Department of Energy Technology, Aalborg University, 2014. Department of Energy Technology, Aalborg University. 
Roemer, D. B., Johansen, P., Pedersen, H. C., and Andersen, T. O. Design and modelling of fast switching efficient seat valves for digital displacement pumps. Transactions of the Canadian Society for Mechanical Engineering, 2013. 37(1):71-88. doi:10.1139/tcsme2013-0005.

Roemer, D. B., Johansen, P., Pedersen, H. C., and Andersen, T. O. Oil Stiction in Fast Switching Annular Seat Valves for Digital Displacement Fluid Power Machines. In Proceedings of the 12th Biennial Conference on Engineering Systems Design and Analysis. 2014. doi:10.1115/ESDA2014-20443.

Roemer, D. B., Johansen, P., Pedersen, H. C., and Andersen, T. O. Fluid Stiction Modeling for Quickly Separating Plates Considering the Liquid Tensile Strength. Journal of Fluids Engineering, 2015a. doi:10.1115/1.4029683.

Roemer, D. B., Johansen, P., Schmidt, L., and Andersen, T. O. Modeling of Movement-Induced and FlowInduced Fluid Forces in Fast Switching Valves. In Inter. Conf. Fluid Power and Mechatronics. 2015b. doi:10.1109/FPM.2015.7337257.

Salter, S. H., Taylor, J. R. M., and Caldwell, N. J. Power conversion mechanisms for wave energy. Journal of Engineering for the Maritime Environment, pp. 1-2\%, 2002. doi:10.1243/147509002320382103.

Schmidt, L., Roemer, D. B., Pedersen, H. C., and Andersen, T. O. Speed-variable switched differential pump system for direct operation of hydraulic cylinders. Proceedings of ASME/BATH 2015 Symposium on Fluid Power and Motion Control, American Society of Mechanical Engineers, 2015. doi:10.1115/FPMC2015-9575.

Sniegucki, M., Gottfried, M., and Klingauf, U. Optimal control of digital hydraulic drives using mixedinteger quadratic programming. Proceedings of the 9th IFAC Symposium on Nonlinear Control Systems, 2013. doi:10.3182/20130904-3-FR-2041.00013.

Song, X. Modeling and active vehicle suspension system with application of digital displacement pump motor. Proceedings of the ASME 2008 International Design Engineering Techical Conferences \&6 Computers and Information in Engineering Conference, New York, USA, 2008. doi:10.1115/DETC200849035.

Teel, A. R., Sanfelice, R. G., and Goebel, R. Feedback control of hybrid dynamical systems. Encyclopedia of Systems and Control, 2015. doi:10.1007/978-1-44715102-9_271-2. 